\title{
Salicylic acid in the serum of subjects not taking aspirin. Comparison of salicylic acid concentrations in the serum of vegetarians, non-vegetarians, and patients taking low dose aspirin
}

\author{
C J Blacklock, J R Lawrence, D Wiles, E A Malcolm, I H Gibson, C J Kelly, J R Paterson
}

\begin{abstract}
Aims-To determine serum salicylic acid concentrations in non-vegetarians and vegetarians not taking salicylate drugs, and to compare these concentrations with those found in patients taking aspirin, $75 \mathrm{mg}$ daily.
\end{abstract}

Methods-Serum samples were obtained from vegetarians $(n=37)$ and nonvegetarians $(n=39)$ not taking salicylate drugs. Non-vegetarians and vegetarians were recruited from the community and from a Buddhist monastery, respectively, in Dumfries and Galloway, Scotland. Patients $(\mathbf{n}=14)$ taking aspirin $(75 \mathrm{mg}$ daily) were recruited from the Dumfries diabetic clinic. Serum salicylic acid concentrations were determined using a high performance liquid chromatography method with electrochemical detection.

Results-Salicylic acid was detected in every serum sample analysed. Higher serum concentrations of salicylic acid were found in vegetarians than nonvegetarians: median concentrations of 0.11 (range, 0.04-2.47) $\mu \mathrm{mol} / \mathrm{litre}$ and 0.07 (range, 0.02-0.20) $\mu \mathrm{mol} / \mathrm{litre}$, respectively; the median of the difference was 0.05 $\mu \mathrm{mol} / \mathrm{litre}$ (95\% confidence interval for difference, 0.03 to $0.08 ; p<0.0001$ ). The median serum concentration of salicylic acid in patients taking aspirin $(75 \mathrm{mg}$ daily) was 10.03 (range, $0.23-25.40$ ) $\mu \mathrm{mol} /$ litre, which was significantly higher than that found in non-vegetarians and vegetarians. There was overlap in serum salicylic acid concentrations between the vegetarians and patients taking aspirin. Conclusions-Salicylic acid, a nonsteroidal anti-inflammatory drug, is present in fruits and vegetables and is found in higher concentrations in vegetarians than non-vegetarians. This suggests that a diet rich in fruits and vegetables contributes to the presence of salicylic acid in vivo. There is overlap between the serum concentrations of salicylic acid in vegetarians and patients taking aspirin, $75 \mathrm{mg}$ daily. These findings may explain, in part, the health promoting effects of dietary fruits and vegetables. (f Clin Pathol 2001;54:553-555)
Keywords: salicylic acid; salicylates; diet; low dose aspirin

Over the past few decades, evidence has emerged to suggest that regular aspirin use reduces the risk of cardiovascular disease ${ }^{1}$ and of developing colorectal cancer, ${ }^{2}$ and that it might also reduce the risk of developing lung and breast cancer ${ }^{34}$ and Alzheimer's disease. ${ }^{5}$ In vivo, aspirin probably acts as an antiinflammatory prodrug, with the active component being salicylic acid (SA). ${ }^{67}$ The risks of developing colorectal cancer and cardiovascular disease are also lower in those who consume diets rich in fruits and vegetables, although the chemical components responsible have not been identified. Nutritional research has centred on identifying the fruit and vegetable components that are responsible for those health benefits but these remain, as yet, elusive. ${ }^{8}$ Recently, we identified SA and two other salicylates-2,3-dihydroxybenzoic acid and 2,5-dihydroxybenzoic acid-as normal constituents of serum in subjects not consuming salicylate drugs; because these compounds are components of fruits and vegetables, we speculated that they originate from dietary plant sources. ${ }^{10}$ Because aspirin is a prodrug of $\mathrm{SA},{ }^{67}$ and a diet rich in fruits and vegetables appears to help prevent similar conditions to aspirin, we sought quantitative evidence that might support SA as the common factor. Only one other study has investigated salicylates in humans not taking salicylate drugs, measuring urinary "total salicylates" in 17 volunteers. ${ }^{11}$ Hydrolysis of urine with subsequent analysis, however, provides no information on the concentrations of SA found in blood or in tissue, especially because SA is metabolised and salicylates may be concentrated in urine.

We have developed a method to measure SA in sera from volunteers not consuming salicylate drugs and have determined serum concentrations in non-vegetarians, vegetarians, and patients taking aspirin, $75 \mathrm{mg}$ daily.

\section{Methods}

VOLUNTEERS AND PATIENTS

Non-vegetarians $(n=39 ;$ mean age, 40.5 years; SD, 10.9; 21 men) were recruited from the community in Dumfries and Galloway, southwest Scotland. Vegetarians $(n=37$; mean age, 41.7 years; SD, 10.5; 24 men) were
Accepted for publication 4 January 2001
Area Biochemi
Department, D
and Galloway
Infirmary, Ban
Road, Dumfries,
Scotland, DG1
UK
C J Blacklock
D Wiles
J R Paterson
Department of
Medicine, Dum
and Galloway
Infirmary
J R Lawrence
E A Malcolm
C J Kelly
Department of
Pathology, Dum Infirmary

Correspondence to: Dr Paterson

J.Paterson@dgri.scot.nhs.uk 


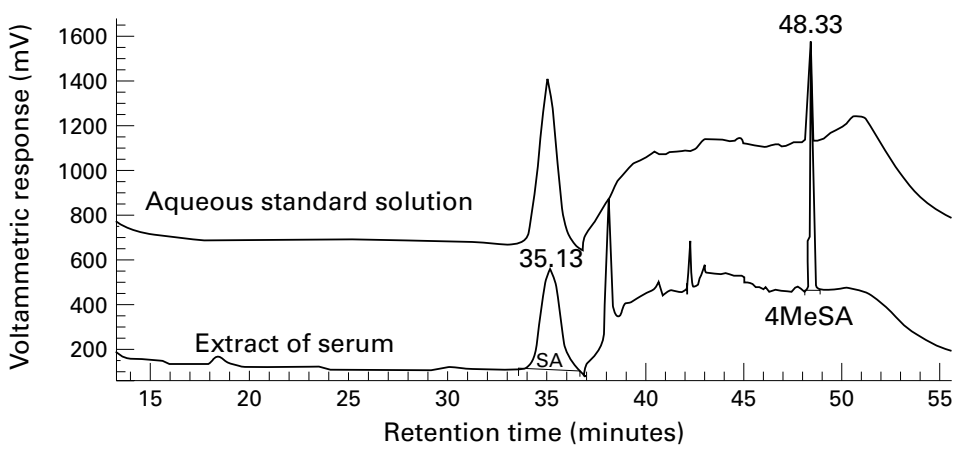

Figure 1 High performance liquid chromatography chromatograms of an extract of serum and of an aqueous standard solution of salicylic acid (SA) and 4-methylsalicylic acid (4-MeSA).

recruited from a group of Buddhist monks, of European origin, who were in retreat (being catered for from a communal kitchen) at the Samye Ling Monastery in Upper Eskdale, southwest Scotland. Patients taking aspirin, $75 \mathrm{mg}$ daily $(\mathrm{n}=14$; mean age, 58.9 years; $\mathrm{SD}$, 12 ; seven men) were recruited from the Dumfries diabetic clinic. In this last group the median time between aspirin ingestion and venesection was 215 minutes (range, 1051200). A drug history was obtained in the nonvegetarians and vegetarians to ensure no volunteer was taking salicylate drugs. Blood samples (non-fasting) were taken in the morning from the vegetarians and patients, and from most of the non-vegetarians, although in this last group some samples were taken in the afternoon. Venous blood samples were allowed to coagulate before separating the serum by centrifugation $(2000 \times g$ for 10 minutes $)$. Serum samples were then stored at $-28^{\circ} \mathrm{C}$. These investigations were approved by the local research ethics committee and informed consent was obtained.

ANALYSIS

The analysis of serum samples for SA was carried out by high performance liquid chromatography (HPLC) with electrochemical detection, as described previously, ${ }^{10}$ but with the following modifications. Briefly, we added EDTA (final concentration of $100 \mu \mathrm{mol} /$ litre), 4-methyl SA (internal standard, final concentration of $2.0 \mu \mathrm{mol} / \mathrm{litre})$, and $\mathrm{HCl}(1.0 \mu \mathrm{mol} /$ litre) to $0.5 \mathrm{ml}$ aliquots of serum to produce a $\mathrm{pH}$ of $2.0 ; 2.0 \mathrm{ml}$ of ethyl acetate was then added. The extraction tubes were shaken for 15 minutes, centrifuged at $2000 \times g$ and the organic phase removed. The extraction was repeated and the combined organic phases evaporated to dryness at $70^{\circ} \mathrm{C}$ under oxygen free nitrogen. The combined extracts were reconstituted in HPLC mobile phase B containing EDTA (final concentration of $1.0 \mu \mathrm{mol} /$ litre). The proportions of two mobile phases (A: $50 \%$ methanol (vol $/ \mathrm{vol}$ ) in citrate buffer, $30 \mathrm{mmol} /$ litre, $\mathrm{pH}$ 4.0; $\mathrm{B}: 1 \%$ methanol (vol/vol) in citrate buffer, $30 \mathrm{mmol} /$ litre, $\mathrm{pH}$ 3.8) in the elution mixture were modified in a four step programme, namely: (1) $0-5$ minutes $(25 \% \mathrm{~A}, 75 \% \mathrm{~B})$; (2) 5-28 minutes $(0 \% \mathrm{~A}, 100 \% \mathrm{~B})$; (3) $28-43$ minutes $(100 \% \mathrm{~A}$, $0 \% \mathrm{~B}$ ); and (4) 43-58 minutes (25\% A, 75\%
Table 1 Serum concentrations of salicylic acid ( $\mu$ mol/litre) in non-vegetarians, vegetarians, and patients taking aspirin (75 mg daily)

\begin{tabular}{lll}
\hline Non-vegetarians & Vegetarians & Patients taking low dose aspirin \\
\hline 0.07 & $0.11^{\star}$ & 10.03 \\
$(0.02-0.20)$ & $(0.04-2.47)$ & $(0.23-25.40)$ \\
$\mathrm{n}=39$ & $\mathrm{n}=37$ & $\mathrm{n}=14$
\end{tabular}

Values are median (range).

* Significantly greater than non-vegetarians, median of the difference $0.05 \mu \mathrm{mol} / \mathrm{litre}(95 \%$ confidence interval for difference, 0.03 to $0.08 ; \mathrm{p}<0.0001)$.

B). The prodigy ODS 3 HPLC column was maintained at $30^{\circ} \mathrm{C}$. Before use, all glassware was rinsed in double distilled water followed by single distilled acetone. Each sample was analysed in duplicate. The intra-assay coefficient of variation (CV) was $7 \%$ at a serum SA concentration of $0.059 \mu \mathrm{mol} /$ litre (10 determinations) and the interassay $\mathrm{CV}$ was $6 \%$ at a serum SA concentration of $0.095 \mu \mathrm{mol} /$ litre (six assays carried out on six different days). SA was not detected when water samples were analysed using the same needles, syringes, and blood collection tubes as used for serum samples.

STATISTICAL ANALYSIS

Serum SA concentrations were not normally distributed and median values (range) are reported. Non-parametric analysis was carried out using the Mann Whitney U test.

\section{Results}

SA was completely resolved from other compounds, having a retention time of approximately 32-35 minutes (fig 1), and was found to be present in every serum sample analysed. Higher serum concentrations of SA were found in vegetarian volunteers than in nonvegetarians (table 1); the median of the difference was $0.05 \mu \mathrm{mol} /$ litre $(95 \%$ confidence interval for difference, 0.03 to 0.08 ; $\mathrm{p}<0.0001)$. There was overlap in the serum concentrations between the vegetarian group and the aspirin group. Eight of the 37 vegetarians had serum SA concentrations above the lowest serum SA concentration found in the aspirin group and six of the 14 patients in the aspirin group had serum SA concentrations below the highest vegetarian value. However, there was a large variation in the SA concentrations within each of these groups, with the aspirin group having a median SA concentration approximately 100 times greater than that of the vegetarian group.

\section{Discussion}

This is the first study to measure serum SA concentrations in subjects not taking salicylate drugs. Our main findings were that SA was present in every serum sample analysed, and that sera from vegetarians had higher SA concentrations than those obtained from nonvegetarians. This suggests that fruits and vegetables contribute to the presence of SA in vivo. Many fruits and vegetables contain salicylates but, in particular, herbs and spices contain the greatest concentrations. ${ }^{12}$ We found 
a large variation in the serum SA concentrations within both the vegetarian and aspirin groups. In the last group, the blood sampling time post-dose probably explains some of the variation. It is more difficult to explain the large variation seen in the vegetarian group who were fed the same meals and all of whom were bled within a single two hour session. The samples, however, were non-fasting and the serum SA concentrations may have been influenced by the timing of the specimens relative to breakfast. In this respect the difference between the non-vegetarians and vegetarians may be an underestimate because some of the samples from the first group were taken in the afternoon.

Studies are needed to establish the biological effects of the concentrations of SA found in the vegetarian and non-vegetarian volunteers not taking aspirin. Other investigators have considered dietary salicylate intake as unimportant because dietary salicylates are not in the form of aspirin. ${ }^{11}$ The antiplatelet action of aspirin is not shared by the other salicylates. However, most cardiovascular disease is the result of atherosclerosis, a chronic inflammatory disease process. ${ }^{13} \mathrm{SA}$ is an anti-inflammatory drug that was used clinically before aspirin, with recent work showing that the anti-inflammatory action of aspirin is the result of its predominant metabolite, SA. ${ }^{67} \mathrm{SA}$ inhibits the transcription of cyclooxygenase 2 (COX 2), a key enzyme involved in inflammation and certain cancers. The inhibition of COX 2 transcription has been shown to occur at SA concentrations as low as $0.1 \mu \mathrm{mol} /$ litre, concentrations that we have found in volunteers not taking salicylate drugs, especially vegetarians.

Further evidence to support the view that the serum concentrations of SA found in vegetarians may have biological effects is found in the overlap between vegetarians and patients taking aspirin. Ruffin et al have shown that low dose aspirin (equivalent to $31 \mathrm{mg} \mathrm{SA}$ ) reduced prostaglandin $\mathrm{F} 2 \alpha$ concentrations in colorectal mucosa at 24-30 and 72-78 hours after the last dose of aspirin. ${ }^{14}$ The mean peak plasma SA concentration measured was 11.8 (SD, 8.18) $\mu \mathrm{mol} /$ litre in this group and the large standard deviation indicates a wide range of plasma SA concentrations in subjects taking the same dose of aspirin. At an aspirin dose of $81 \mathrm{mg}$ daily, mucosal prostaglandin concentrations of both E2 and F2 $\alpha$ were decreased. ${ }^{14}$
The results of our study highlight the presence of SA in blood, probably originating from fruits and vegetables. The presence of SA, especially in vegetarians, was at concentrations that are known to inhibit the transcription of COX 2, a key inflammatory enzyme in various pathologies. SA concentrations also overlapped with those measured in patients taking aspirin, $75 \mathrm{mg}$ daily. If the anti-inflammatory actions of $\mathrm{SA}$ at these concentrations can be confirmed in vivo, it is possible that dietary salicylates will prove to be one of the reasons why diets rich in fruits and vegetables protect against colorectal cancer and cardiovascular disease.

We wish to thank the doctors and patients of the general practices in Dumfries (33 Castle Street), Sanquhar, and Wigtown, and the Buddhist monks at the Samye Ling centre, the diabetic patients attending the diabetic clinic at Dumfries and Galloway Royal Infirmary, Dr M Murphy, and Dr M McMahon for helpful comments on the manuscript, and P Moore for secretarial assistance. The authors gratefully acknowledge the financial assistance of Newton Stewart and District Branch of the BDA,
Dumfries and Galloway Acute and Maternity Hospitals NHS Dumfries and Galloway Acute and Maternity Hospitals
Trust, and the Chief Scientist's Office, Edinburgh, UK.

1 Antiplatelet Trialists' Collaboration. Collaborative overview of randomised trials of antiplatelet therapy. I: Prevention of death, myocardial infarction, and stroke by prolonged antiplatelet therapy in various categories of patients. BMF 1994;308:81-106.

2 Marcus AJ. Aspirin as the prophylaxis against colorectal cancer. N Engl F Med 1995;333:656-8.

3 Schreinmachers DM, Everson RB. Aspirin use and lung, colon, and breast cancer incidence in a prospective study. Epidemiology 1994;5:138-46.

4 Vainio H, Morgan G. Cyclo-oxygenase 2 and breast cancer prevention. BMF 1998;317:328

5 Rich JB, Rasmusson DX, Folstein MF, et al. Nonsteroidal anti-inflammatory drugs in Alzheimer's disease. Neurology 1995; 45:51-5.

6 Higgs GA, Salmon JA, Henderson B, et al. Pharmacokinetics of aspirin and salicylate in relation to inhibition of arachidonate cyclooxygenase and anti-inflammatory activity. chidonate cyclooxygenase and anti-inflamm
Proc Natl Acad Sci U S A 1987;84:1417-20.

7 Xu X-M, Sansores-Garcia L, Chen X-M, et al. Suppression of inducible cyclooxygenase 2 gene transcription by aspirin nd sodium salicylate. Proc Natl Acad Sci USA 1999;96:5292-7.

8 Stavric B. Role of chemopreventers in human diet. Clin Biochem 1994;27:319-22.

9 Greenberg ER, Sporn MB. Antioxidant vitamins, cancer, and cardiovascular disease. N Engl f Med 1996;334:118990.

10 Paterson JR, Blacklock CJ, Campbell G, et al. The identification of salicylates as normal constituents of serum: a link between diet and health? I Clin Pathol 1998;51:502-5.

11 Janssen PLTMK, Hollman PCH, Reichman E, et al. Urinary salicylate excretion in subjects eating a variety of diets shows that amounts of bioavailable salicylates in foods are low. Am f Clin Nutr 1996;64:743-7.

12 Venema DP, Hollman PCH, Janssen PLTMK, et al. Determination of acetylsalicylic and salicylic acid in foods, using HPLC with fluorescence detection. $f$ Agric Food Chem 1996;44:1762-7.

13 Ross R. Atherosclerosis-an inflammatory disease. $N$ Engl f Med 1999;340:115-26.

14 Ruffin MT, Krishman K, Rock CL, et al. Suppression of human colorectal mucosal prostaglandins: the lowest effective aspirin dose. F Natl Cancer Inst 1997;8:1152-60. 